\title{
Non-State Actors in Maritime Security
}

a One Earth Future Policy Brief

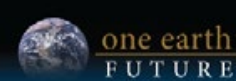

based on a chapter from the book

Strengthening Maritime Security Through Cooperation

Policy Implications:

Security institutions should consider developing formal or informal informationsharing systems with maritime actors in the geographic or functional areas where they operate.

Stakeholders in a specific maritime problem, whether state or nonstate, should consider the full spectrum of potential roles for nonstate actors.

The process of developing engagement between state and nonstate actors around security challenges can take time.

There is a distinct role for nonstate actors to extend the capacity of existing security institutions. 


\section{Non-State Actors in MARITIME SECURITY}

\section{RESEARCH BACKGROUND}

As part of an ongoing lessons-learned project based on Oceans Beyond Piracy's work with the Contact Group on Piracy off the Coast of Somalia, One Earth Future is documenting the potential role of nonstate actors in maritime security. Based on this work, in November 2014 OEF research staff participated in a research workshop organized under the NATO Science for Peace and Security Program. This workshop focused on questions of communication and coordination in maritime security, with an eye to improving NATO maritime strategy and maritime security more broadly. One outcome of this workshop was the volume Strengthening Maritime Security Through Cooperation, edited by Ioannis Chapsos and Cassie Kitchen and published by IOS press. Conor Seyle and Jens Madsen contributed a chapter on the role of nonstate actors in maritime security, based on both analysis of existing research in peace and security and also the experiences of OBP as a nonstate actor working in the area of maritime piracy. This brief reviews the argument and describes policy recommendations that arise from this analysis.

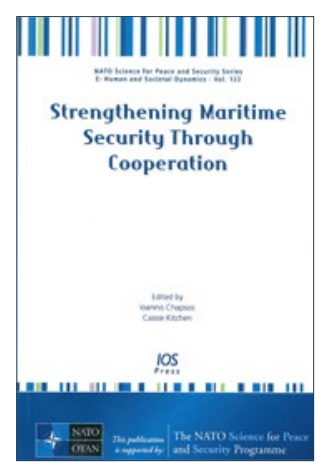

Strengthening Maritime Security Through Cooperation, a volume of the NATO Science for Peace and Security Series. Ioannis Chapsos and Cassie Kitchen, eds. August 2015

Chapter 3

\section{LINK TO BOOK}




\section{Research Summary}

The navies, coast guards, and other security institutions that directly engage questions of maritime security are embedded in larger national security and military structures. Because of this, questions of maritime security can be influenced by trends in security strategy and practice overall. In addition, the specific demands of maritime security create unique pressures that influence its strategy and practice, including challenges of maritime domain awareness and the large operational space in which maritime actors work. An analysis of trends in maritime security therefore should incorporate an analysis of both the specific needs of the maritime environment and also larger security trends.

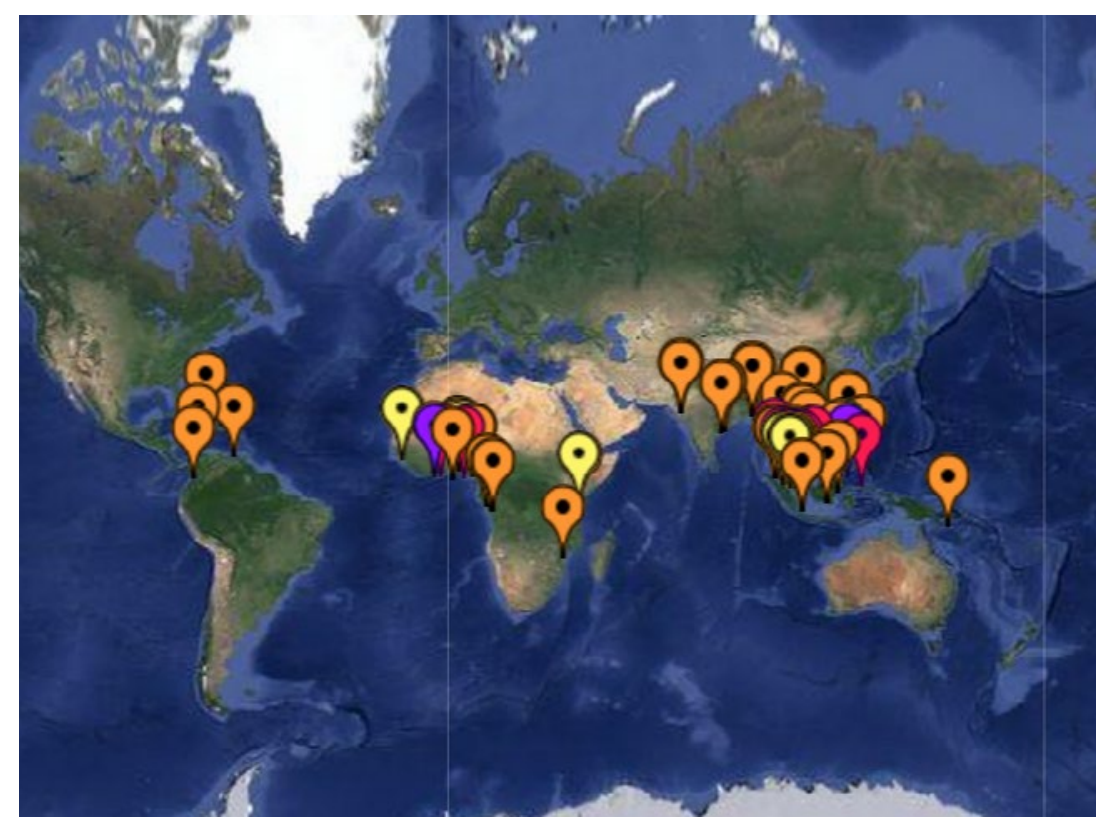

International Maritime Bureau Piracy and Armed Robbery Map 2015, https://icc-ccs.org/.

In considering questions about the role of nonstate actors in maritime security, both pieces - larger security trends and also the specific demands of maritime security - have elements that push toward a greater engagement of nonstate actors in maritime security than has historically been identified. This is because of a general trend toward more engagement with nonstate actors by security institutions overall, and also because the relatively tight community of maritime stakeholders and the visibility of private-sector actors in the maritime domain suggest that there may be a larger role for nonstate actors in supporting maritime security than in terrestrial security issues.

In the first case, there have been several shifts in security studies and practice supporting engagement with nonstate actors. As the drivers of violence internationally have shifted away from major stateto-state conflict and toward substate conflicts and violence driven by nonstate actors, there has been a corresponding shift in discussing security in broader terms such as "soft" or "human" security challenges. ${ }^{1}$ This definition encompasses issues such as substate violence, terrorism, and state stability, and the diagnoses and solutions to these challenges necessarily involve nonstate actors more directly than traditional definitions of security focused on military conflict. Alongside this shift, there has also been a shift in institutional structures used to address international security challenges. There has been a proliferation of network-based structures as compared to more traditional hierarchical and treaty-based structures. ${ }^{2}$ These systems are less formal with much easier pathways to entry and exit, and have more flexible but less codified operations. Such structures make it easier for nonstate actors to participate than more formal organizations with codified rules for membership. One example of such a structure, directly relevant to maritime security, is the network structure of the Contact Group on Piracy off the Coast of Somalia. A CGPCS participant who described this network structure argued that it was key to the ability of the CGPCS to develop nimble responses to the problem of piracy and that the group would "never have worked in a formal setting." 3 The trends in security theory and practice overall have therefore been toward focusing on issues where nonstate actors in general have things to add, and developing structures that make it easier for nonstate actors to participate.

The specific requirements of the maritime domain also create pressure for the inclusion of nonstate actors. The enormous sizes of naval areas of operation create challenges in maintaining force projection and situational awareness, and the inclusion of nonstate actors in information sharing can act to support security. In addition, the relatively small number of commercial and nongovernmental organization entities that work in the maritime domain compared to land-based situations makes it much easier to identify relevant stakeholders and coordinate them toward addressing problems. At the same time, the high seas are a global commons in which there is no single state responsible for enforcing laws; stakeholders concerned about maritime issues are required to 
work together to address problems rather than turn to a single state to resolve them. Taken together, these elements suggest that there may be a valuable role for nonstate actors in extending the capacities of maritime security institutions, and it may be easier to engage nonstate actors in the maritime domain than in shore-based issues.

The remainder of the research reviewed what roles nonstate actors have played in maritime security. The authors identified three general roles for nonstate actors: advocacy and agenda-setting, provision of logistical and institutional support to security systems, and the direct provision of security services. In the first case, advocacy and agenda-setting are traditional roles of nonstate actors. Through mobilizing communities of interest to put normative, political, or economic pressure on other institutions, nonstate actors can have an impact on international security agendas. In the maritime sector, maritime industry actors effectively pressured states to consider piracy a problem that required a formal response: public pressure campaigns like the International Transport Workers' Federation's "Save Our Seafarers" campaign were part of the early discussion around piracy. Nonstate private diplomacy can also be a function of agenda-setting and advocacy. Rather than public pressure, this approach involves the coordination of stakeholders to identify shared interests and engagement with a specific proposed solution. In the maritime sector, nonstate actors including Oceans Beyond Piracy and the International Maritime Bureau played a role in encouraging the drafting and signing of the Declaration Condemning Acts of Violence Against Seafarers by several major flag states. This declaration contributes to the coordination of counter-piracy activities and the reporting of pirate attacks.

A second pathway for nonstate actors' participation in security is through the provision of support services to security institutions. NGOs and private companies have historically played significant roles in logistical support for security institutions, and in particular in providing humanitarian support for

those impacted by violence. There is also a developing role for nonstate actors to act as "backbone support"4 organizations for network security institutions. In this role, nonstate actors provide organizational and administrative support for the coordination of multiple actors. In the maritime sector, nonstate actors have taken on both direct support and backbone support roles. NGOs have been heavily involved in the humanitarian element of supporting pirate hostages both during their captivity and after release. Many organizations have also played backbone support roles. One clear example is the role of the International Maritime Bureau Piracy Reporting Center in supporting maritime situational awareness. The IMB PRC operates to coordinate the reporting of pirate attacks from both private and state actors, and functions as a central clearinghouse for information sharing. In doing this, it operates in support of the larger network of counter-piracy structures.

The third, and most controversial, pathway to participation in maritime security by nonstate actors is through the direct provision of security services. Private military and security companies (PMSCs) provide security services including both combat support 
and direct combat operations, and are an increasingly prominent feature of modern conflicts. ${ }^{5}$ Transnational corporations, by the nature of their operations, also frequently intersect directly with the political dynamics supporting conflict, and can shape their operations and their political engagement to support peace rather than violence. ${ }^{6}$ In the maritime sector, there has been direct engagement of nonstate actors with security provision in counter-piracy. One element of the response to Somali piracy was the proliferation of armed guards provided by private companies: it is estimated that as many as 50 percent of all transits in the region have armed guards aboard. ${ }^{7}$ While the direct impact of armed guards on the decline of piracy is hard to establish, no vessel with armed guards aboard has been captured off the coast of Somalia and it's highly likely that the use of armed guards contributed to the decline in piracy in that region.

The chapter also acknowledges the controversies associated with bringing private-sector actors into security discussions, including the criticism that state and legal institutions are the only legitimate institutions to address security issues, and resistance from private-sector actors to engage in activities other than their core businesses. However, despite this criticism the cases provided here suggest that there is a distinct role for nonstate actors to extend the capacity and abilities of existing security institutions.

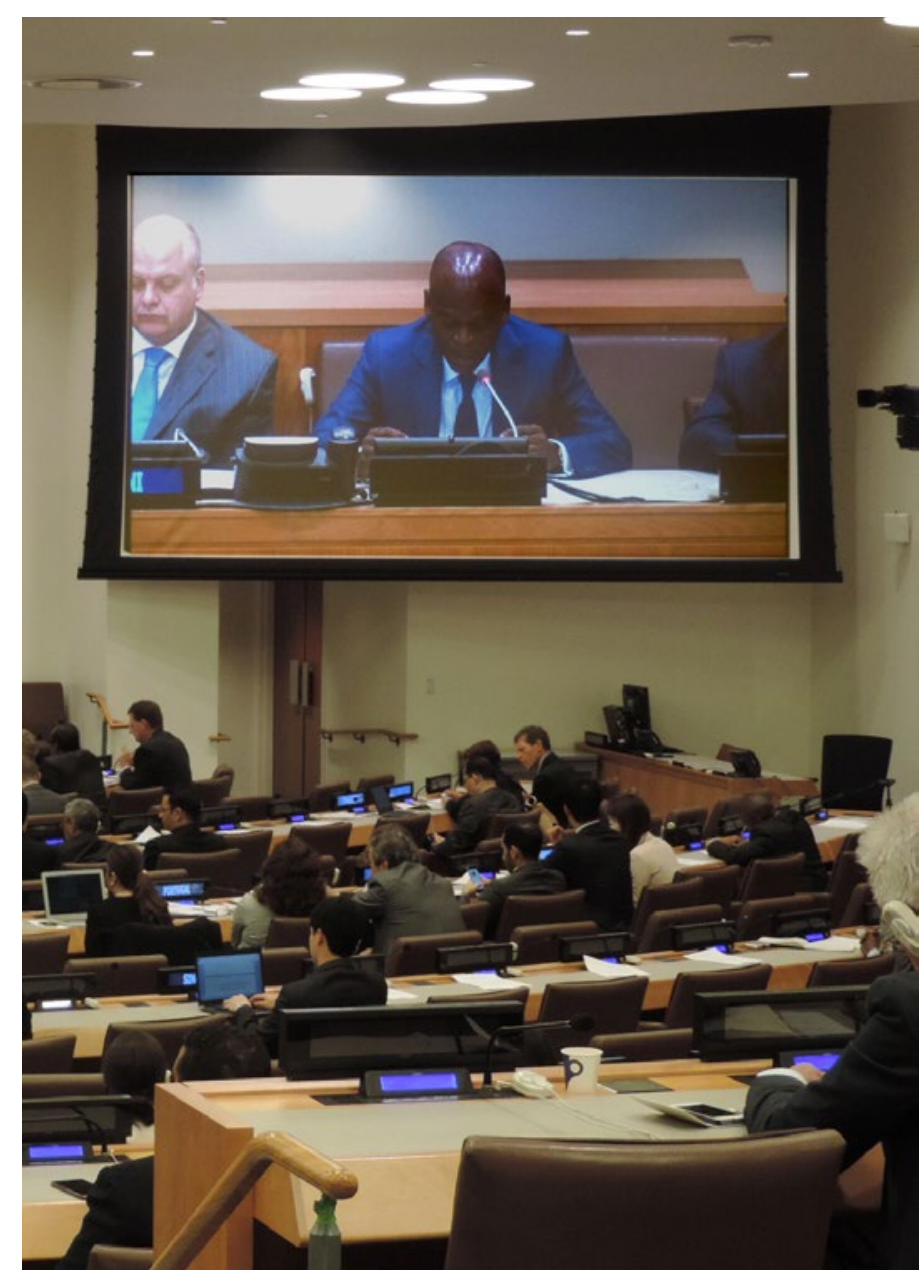

Above: HEM Robert Dussey, Minister of Foreign Affairs for the Republic of Togo, speaking at the CGPCS Plenary Meeting, July 2015. Photo by Jérôme Michelet

Below: London event condemning violence against seafarers in support of the Washington Declaration, September 2014. Photo by Tania Payne.

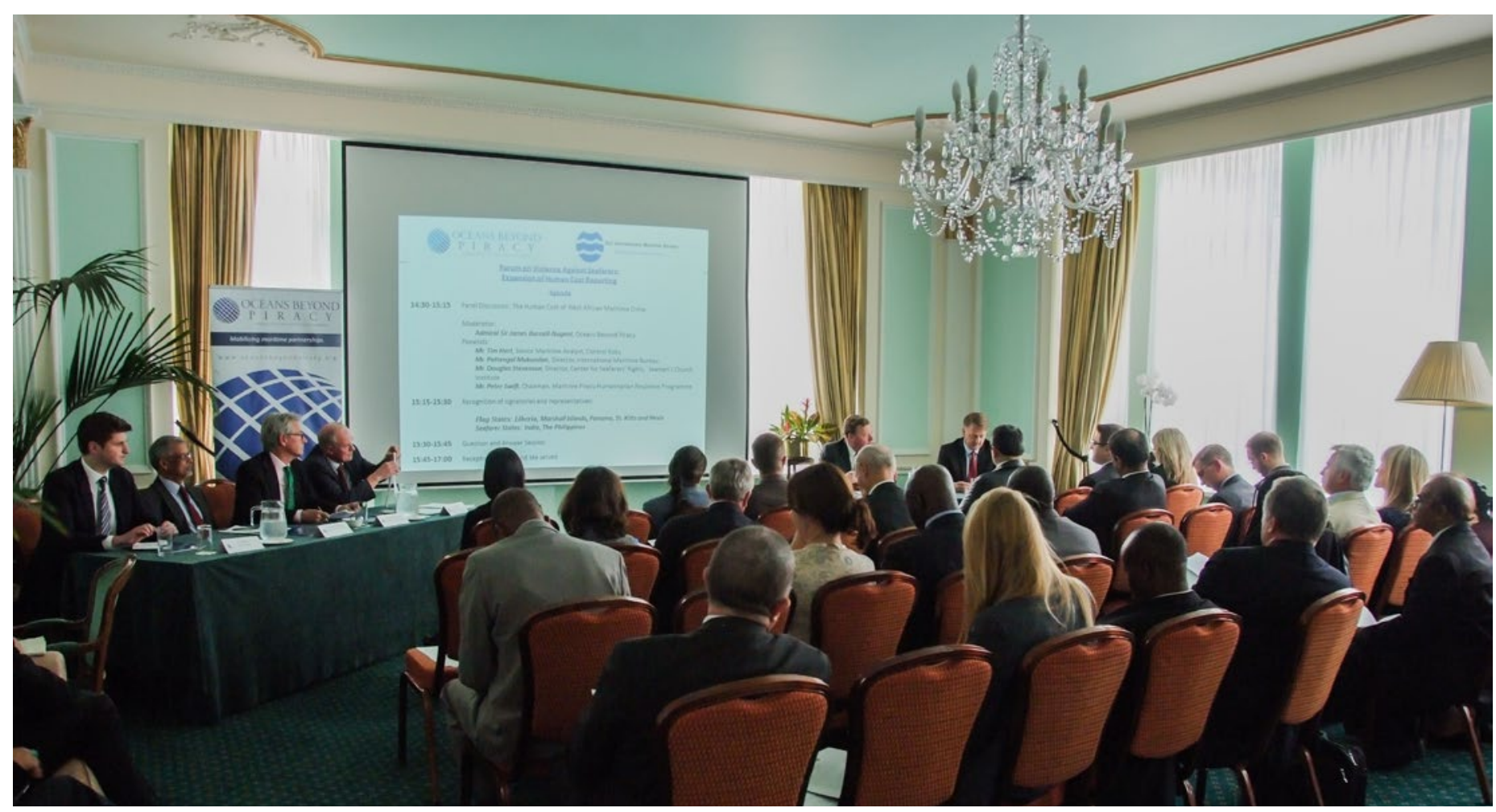


One Earth Future $(\mathrm{OEF})$ is a private foundation founded to help catalyze systems that identify and eliminate the root causes of war. OEF is committed to improving governance structures by acting at the intersection of theory and practice, helping stakeholders solve specific problems in real time, contributing to research literature, and working to detect patterns and lessons about governance as they emerge. Instilled within OEF's work are values of excellence, empiricism, long-term thinking, and active stakeholder engagement.

The OEF policy brief series provides distillations of research lessons into practical recommendations for policy and practice.

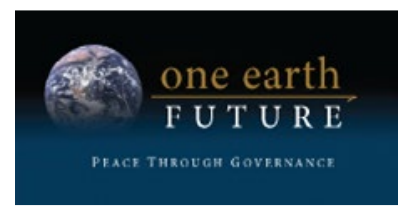

ONE EARTH FUTURE FOUNDATION

525 Zang Street

Broomfield, CO 80021 USA

www.oneearthfuture.org 